\title{
Evandro de Oliveira: from Anatomy to Science and the Art of Microneurosurgery
}

\author{
Sebastião Gusmão ${ }^{1}$ \\ 1 Universidade Federal de Minas Gerais, Belo Horizonte, Minas Gerais, \\ Brazil
}

Arq Bras Neurocir 2021;40(1):30-32.

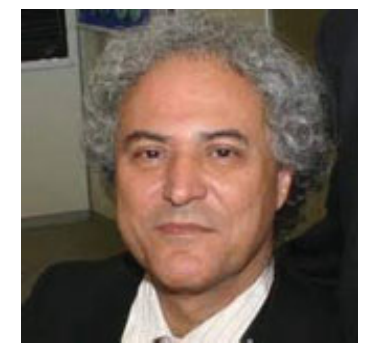

Sebastião Gusmão
It is classic to state: medicine is science and art. Medicine and art go hand in hand. Hippocrates's medicine(460-378 BC) was born during Pericles century (495-429 BC), at the nadir of Greek art of Fidias (490-430 BC). Both submerged during the middle ages and reburned during the Italian renaissance.

Science can be defined like organized knowledge and be confirmed through observation and experimentation. However, it is difficult to define art because the term could mean multiple things in different places and time. The greek term tékhné, translated to latin as technique and also as art.The later meaning, whatever is well done by the man. For the greeks artwork was to perform a technique with excellence. Hence, in the first Hippocrates's aphorism, "The life is short, the art last long.”(ÓBios brakhys É dé tékhné makhré), the term tékné refers to art meaning technique acquisition, practical knowledge the execution of work in the medical field.

In all branches of knowledge, including medicine and surgery, there archaic civilizations referred to medicine as art, or better as technique based in mythical explanation. The "Greek miracle" exclude the mythical explanation and submitted the technical knowledge to the sieve of rationality, creating Science as we know. Therefore, medicine and surgery are old as art but new as science. In reality, way before the emergence of science in Greece at the $6^{\text {th }}$ century B.C., the Neolithic man already had practiced the art of surgery as documented in several trephined skulls found in several different archeological sites.

The intimate relation between technique and science in the pre-Socratic Greece was ruptured by Plato is(428-348 B. C.) philosophy, which was disputed by the intellectual capacity of the technicians.

This fact determined the discredit of the manual labor, including plastic artists, during the medieval and classic period, being one of the main reasons for the dichotomy between theory and practice, science and technic, medicine (scientific knowledge) and surgery (technical knowledge). This dichotomy increased with the medieval scholars. Only during the Renaissance the artist and handcrafters recuperated their dignity and prestige.

The Vesalius"s (1514-1564) dissections depicted in De Humani Corpori Fabrica (1543), inaugurate the modern medicine. In his work, still considered the most outstanding in medicine, the narrow relation between science and art takes place.

The Vesalius' text is as important as the exquisite illustrations of Calcar (1499-1546), Tiziano's disciple. Therefore we can say that modern medicine was born in an anatomy laboratory and in the workshop of a renaissance painter.

The word surgery came from the Greek kheir, hand, and ergon, "work" .Until the XVI century, surgery was only manual labor, without scientific bases, and wasn't performed by doctors but by barber surgeons. Ambroise Paré (15101590) saw the new Vesalius's anatomy as the foundation of surgery. He transformed the barber-surgery art into the medieval art and science of surgery, giving the dignity and respect towards to the surgeon's work.

In the Seventeenth century, the knowledge acquired in the two previous renaissance centuries increased even more, leading to the birth of the modern science.

In this context neurosciences was born in 1664, with the work named Cerebri Anatome from Willis (1621-1675), in which medieval concepts regarding cerebral function were repealed. The pillars of modern neurosciences and neurology were established. As a matter of fact, in this work the word neurology was coined. Again, one more time we witnessed the narrow association between art and science, the outstanding text written by Willis was impeccably illustrated by Christopher Wren (1632-1723), the greatest british artist from all times. Sir Wren, himself, was responsible for the London's reconstruction after the devastating 1666 fire. The Saint Paul cathedral being his masterpiece. Wren's superb
Address for correspondence Sebastião Gusmão, Universidade Federal de Minas Gerais, Belo Horizonte, Minas Gerais, Brazil (e-mail: sebastiaogusmao@gmail.com).
DOI https://doi.org/ 10.1055/s-0041-1730281. ISSN 0103-5355.

\footnotetext{
c) 2021. Sociedade Brasileira de Neurocirurgia. All rights reserved. This is an open access article published by Thieme under the terms of the Creative Commons Attribution-NonDerivative-NonCommercial-License, permitting copying and reproduction so long as the original work is given appropriate credit. Contents may not be used for commercial purposes, or adapted, remixed, transformed or built upon. (https://creativecommons.org/ licenses/by-nc-nd/4.0/) Thieme Revinter Publicações Ltda., Rua do Matoso 170, Rio de Janeiro, RJ, CEP 20270-135, Brazil
} 
drawings revealed great elegance and precision, showing the brain in such detailed and realistic fashion never seen before in any publication.

Subsequently in the Nineteenth century, John Hunter applied experimental scientific method to surgery, creating modern surgery. At the end of the Nineteenth century, advances in general surgery and the better understanding of anatomy and physiology of the nervous system, made possible the creation of neurosurgery as a modern medical specialty.

The modern neurosurgery was born from the hands of an artist-scientist, Harvey

Cushing (1869-1939). The artistic talent from this neurosurgery pioneer was well portraited in his landscape drawings and pictures in his own monumental neurosurgical publications.

On the late half of the last century another scalpel genius, Yasargil, took neurosurgery to another level. Using his extensive and intensive laboratory work he created Microneurosurgery, allowing us to perform miniature art, under microscopic visualization. Indeed, that represented a true revolution in the field, debuting new surgical approaches and better treatment options. Yasargil established several steps. First, the profound and thorough knowledge in central nervous system anatomy. Second, the need of relentless laboratory training and last, but not least, to approach the pathology in the brain in as harmless way as possible through its natural pathways: the sulci and cisterns.

Another essential master to established microneurosurgery was Rhoton. He taught us, using his own exquisite anatomical preparations, to understand better tridimensional brain anatomy and microanatomy and its variations.

Rhoton created a legion of microneuroanatomists that preached their knowledge in all continents. His personal as well as his collaborators endless work constitute the unique preliminary requirement to enter into the science and art of the microneurosurgery world.

His most dear and brilliant pupil was Evandro de Oliveira. After training and conclusion of several projects with his mentor, Evandro returned to Brazil in the earlier eighties. Even before the adventof the internet, he disseminated mocrosurgical knowledge applied to neurosurgery among the Brazilian neurosurgeons. Actually, he initiated a new era of microneurosurgery in his country. To perform microneurosurgery is not just limited to the use of the microscope (which by the way was already present in ours operative rooms. Not too long after that he created the magnificent anatomy laboratory at Beneficência Portuguesa Hospital. For almost four consecutive decades this laboratory has been the main center for microsurgical training for residents and young neurosurgeons. It is for sure a sacred temple for science and art in microneurosurgery. The work of Evandro de Oliveira was without any doubt one of the main factors in the process to raise the Brazilian neurosurgery to the top of the latin-america neurosurgery and to be considered one of the best of the world.

Beyond this essential work in training the last generations of Brazilian neurosurgeons, Evandro de Oliveira developed and improved new microsurgical approaches, shown to our neurosurgery in all four corners of the world and abroad and subsequently opened the doors for many young Brazilian neurosurgeons.

With his skillful hands like a Chinese artist in porcelain from the Ming dynasty, he touched the brain like a priest touches a sacred icon, more so, with his restless brain that kept persuing the brain's misteries, he restored and gave life to thousands of brains. Without passion, life is meaningless. With passion, Evandro took his work to the edges of perfection, turning into pure art. His happiness is to find pleasure in this unique form of art.

It will never be redundant to state how important is the laboratory work in the learning process of microanatomy and surgical technique. Evandro had a fundamental role in improvement in the many generations from Brazil and other countries.

Actually, the modern medicine originated in a laboratory, when Vesalius in1543, performed magnificent dissections to better understand the human body and to illustrate his Fabrica. At the end of the nineteenth century the neurosurgery had its beginning with Horsley. He was summoned to initiate surgical treatment in the neurological patients of the famous Queen Square, due to his notorious skill to open monkey skulls in a laboratory installed in his own house. Yasargil also created microneurosurgery in a laboratory.

The Italian renaissance master painters were in fact the first anatomists. In order to place in canvas the enigmatic face of Monalisa and to carve in pure marble the harmonious lines of David, Leonardo Da Vinci e Michelangelo, they had to dissect cadavers and be aware of the representation object, the human body. In the same fashion, the similar requirements are recommended to the microneurosurgeon. Extreme dedication in studying the anatomy in the laboratory to repair the most complex organic matter ever existent in the universe, the human brain. Only by that way is possible to acquire the mastery in science and art of microneurosurgery.

Five centuries passed by and Vesalius's statement is still true: " the anatomy has to be considered the most solid pilar of the art of medicine, its preliminary essential. The central nervous system anatomy is our preliminary essential in the work field where we practice our job. The brain is the most complex and elaborated matter in our known universe. The brain named itself and creates the universe in which we realized the origin of all forms of arts. Significant art is required from someone that desires to enter in the temple of all arts.

The art has the power to emphasize and refine our senses and to stimulate our awareness in search of occult essence of life's phenomena. The antagonism between art, the daughter of inspiration, and science, originated from methodic observation of facts is only apparent. Art in the Hellenic sense of what is well done and that embroiders all mankind's achievements, including science, because the beauty is everywhere, from a mathematical equation to a Rembrandt (1606-1669) canvas.

Medicine and art complement each other. It is very superficial to imagine a conflict existent between a practical 
art such as surgery, that depends of judgement, intuition and skill, and the precision of science that requires elimination of all human elements. Patient care and treatment of diseases are problems to science, but the excellence in both depends on the art that the doctor applies with scientific knowledge.

In Neurosurgery, the complex central nervous system anatomy, its low threshold for manipulation and the rigidity of the cranium osseous compartment make the challenges even worse, thus requiring refined science and art.

The surgeon in action is no longer a handcrafter that cuts, ligates, detaches or sutures. However, he is not a technician either, but a physician that carries deep knowledge in the human being and his emotional problems and precise domain regarding diseases mechanisms, its diagnostics, pathological manifestations and treatment. Such knowledge, associated with the wisdom originated with experience, it is at the fundaments of abilities in surgical judgement, which is the most difficult requirement to be acquired in the art of surgery.

Our art reflects our life, because nothing can come out from the artist if it is not in the man. Be a good neurosurgeon depends on first in being a good doctor. And what defines a good doctor? Kindness, empathy, conscience, ethics, and the ability to make sensible decisions and make proper judgements, as well as the desire in doing the best for the patient. In the nervous systems there are islands of knowledge, where science can be applied, and a vast ocean where we can only offer hope and comfort. The latter is, a major part of the art of neurosurgery, where we feel and intuit, but can not prove. Like knowledge doesn't resume life, science does not limit medicine. The art is necessary.

The accurate surgical technique, like any other ability, requires repetitive training associated with passion. We can build nothing big without passion. The passion leads to pleasure in our work and that perfects the technique until it meets the art. Therefore excellence in microneurosurgery is a matter of technique, because this originates in the brain of the technician. It is a matter of personality, attitude and character. Those qualities are present in the masters Yasargil and Rhoton. After several years of coexistence and working alongside, I could notice them well in Evandro de Oliveira. His precise microsurgical technique, reached the state of the art, and is nothing more than his character almost paranoid in chase of the truth, the essence of things, the perfect technical detail. On the foundation of all that is the respect to the brain's complexity and the love towards the human being that suffers, generating passion for his duty. According to van Gogh (1853-1890), "The essence of art is the love to the human being." The essence of medicine is the love for the human being that suffers. Only love and art can make existence tolerable, and there is the place that the art of medicine acts. A lot of dignity and humility is necessary from someone whose duty involves love, art and life.

As mentioned above, the master Yasargil, Rhoton and Evandro de Oliveira extensively contributed to the establishment of the art and science of microneurosurgery. The same way Hippocrates removed medicine from the gods temple giving to it mankind, those masters revealed upon us the safe pathways to get in all hidden compartments of the sacred temple of the human brain.

Human knowledge will continue flowing implacably, generating new technologies that probably will reinvent our specialty, that will require from us more science to dominate them and more art to apply them with wisdom in favor of our patient's life and fulfillment of our own. At last, there is only one art undebatable important: to live; everything else is secondary. To our master Evandro de Oliveira, that has helped many in the difficult and dangerous art of living, we can only to thank using the words of the genius of the Portuguese language (Camões): "E mais vos pagamos e mais vos devemos" (The more we pay you, the more we owe you)

\section{Conflict of Interest}

None. 